the European Ceramic Society

Elsevier Editorial System(tm) for Journal of Manuscript Draft

Manuscript Number:

Title: Exceptional micromachining performance of silicon carbide ceramics by adding graphene nanoplatelets

Article Type: SI: WGCC 2016

Keywords: graphene; silicon carbide; ceramic matrix composites; machining; microcomponents

Corresponding Author: Dr. Manuel Belmonte,

Corresponding Author's Institution: Institute of Ceramics and Glass (CSIC)

First Author: Florian Zeller

Order of Authors: Florian Zeller; Claas Müller; Pilar Miranzo; Manuel Belmonte

Abstract: The electrical discharge machining (EDM) performance of silicon carbide (SiC) ceramics is investigated varying their electrical and thermal conductivities by introducing graphene-based fillers.

Sic/graphene nanocomposites with different amounts and types of graphene are manufactured. As graphene flakes appear preferred oriented within the material, the nanocomposites are EDMed in orthogonal directions respecting the graphene basal plane. The addition of graphene nanoplatelets to SiC ceramics dramatically increases the material removal rate (MRR), as compared to monolithic SiC ceramics, allowing the machining of microparts with a fine dimensional precision. A relationship between the EDM response and the transport properties is established, with a strong and direct dependence of MRR with the electrical conductivity of the workpieces, i.e., with the graphene content; while an inverse dependence with the thermal conductivity is observed. The EDM testing orientation of the nanocomposites clearly influences the EDM performance for graphene contents below the electrical percolation threshold.

Suggested Reviewers: Erica Corral

The University of Arizona, USA

elcorraldemail.arizona.edu

Expert on structural ceramics and composites

Young-Wook Kim

The University of Seoul, Republic of Korea

ywkimeuos.ac.kr

Expert on EDM of ceramics

Myung-Chang Kan

Pusan National University, South Korea

kangmc@pusan.ac.kr

Expert on EDM of ceramics 


\title{
Exceptional micromachining performance of silicon carbide ceramics by adding graphene nanoplatelets
}

\author{
Florian Zeller ${ }^{1}$, Claas Müller ${ }^{1}$, Pilar Miranzo ${ }^{2}$, Manuel Belmonte $^{2^{*}}$ \\ ${ }^{1}$ Laboratory for Process Technology, Department of Microsystems Engineering - \\ IMTEK, University of Freiburg, Georges-Köhler-Allee 103, 79110 Freiburg, Germany \\ ${ }^{2}$ Institute of Ceramics and Glass (ICV-CSIC), Kelsen 5, 28049 Madrid, Spain
}

\begin{abstract}
The electrical discharge machining (EDM) performance of silicon carbide (SiC) ceramics is investigated varying their electrical and thermal conductivities by introducing graphene-based fillers. SiC/graphene nanocomposites with different amounts and types of graphene are manufactured. As graphene flakes appear preferred oriented within the material, the nanocomposites are EDMed in orthogonal directions respecting the graphene basal plane. The addition of graphene nanoplatelets to $\mathrm{SiC}$ ceramics dramatically increases the material removal rate (MRR), as compared to monolithic $\mathrm{SiC}$ ceramics, allowing the machining of microparts with a fine dimensional precision. A relationship between the EDM response and the transport properties is established, with a strong and direct dependence of MRR with the electrical conductivity of the workpieces, i.e., with the graphene content; while an inverse dependence with the thermal conductivity is observed. The EDM testing orientation of
\end{abstract}

*Corresponding author. Phone: +34-917355863; Fax: +34-917355843. E-mail: $\underline{\text { mbelmonte@icv.csic.es }}$ (M. Belmonte) 
Keywords: graphene; silicon carbide; ceramic matrix composites; machining; microcomponents

\section{Introduction}

The development of silicon carbide ( $\mathrm{SiC}$ ) ceramic microcomponents to be used, among others, as part of microturbines, microreactors, and microelectromechanical systems or as catalytic microsupports is attracting a great interest mainly due to the excellent thermal, tribological and mechanical performance at high temperature of these ceramics, jointly with their good resistance to corrosive and harsh environments [1,2]. However, the machining of $\mathrm{SiC}$ complex microparts is a complicated task when using diamond grinding wheels, the most common technique, due to the high hardness and brittle nature of $\mathrm{SiC}$, which leads to expensive and time consuming processes for getting microcomponents with relatively low accuracy and surface finishing.

Electrical discharge machining (EDM) arises as one of the most suitable methods to overcome these difficulties, since the material removal is caused by electrical discharges, and mechanical forces between the electrode and the workpiece are not developed [3].The main constraint for EDM is that a minimum electrical conductivity $\left(\sigma_{\mathrm{e}}\right)$ of the workpiece is required $\left(>0.3-1.0 \mathrm{~S} \cdot \mathrm{m}^{-1}\right)$ to enable the electrical discharges [4], which can be a clear limitation in the machining process of $\mathrm{SiC}$ ceramics 
typically exhibiting lower conductivity values than those needed. Different approaches have been considered to enhance the discharge efficiency of ceramics. In this way, Fukuzawa et al. [5] proposed the use of an assisting electrode method (AEM) to machine insulator ceramics by coating the workpiece with a conductive layer. This layer promotes the first discharges between the electrode and the workpiece. The pyrolytic carbon generated during the decomposition of the oil-based dielectric fluid adheres to the ceramic surface, leading to the continuous formation of an intrinsic conductive layer on the workpiece that allows the EDM process. Although AEM has successfully been employed for non-conductive $\mathrm{SiC}$ ceramics [6,7], the material removal rate was low and the electrode wear rate was quite high. Another approach to promote the EDM of low electrical conductive materials consisted in the addition of conductive powders into the dielectric fluid, known as powder mixed EDM (PMEDM) process [8]. Liew et al. [9] improved the electrical discharge frequency and the EDM performance of reaction bonded-SiC (RB-SiC) ceramics by incorporating electrical conductor carbon nanofibers to the dielectric fluid. Finally, successful EDM attempts were carried out in electrically conducting $\mathrm{SiC}$ materials. This is the case of the previously mentioned $\mathrm{RB}-\mathrm{SiC}$ ceramics [10], where the silicon remained after the infiltration process slightly increased $\sigma_{\mathrm{e}}$ up to $\sim 10 \mathrm{~S} \cdot \mathrm{m}^{-1}$, or more noticeably by adding yttrium nitrate as sintering additive into $\mathrm{SiC}$ matrix to achieve $\sigma_{\mathrm{e}}$ values of $\sim 10^{4} \mathrm{~S} \cdot \mathrm{m}^{-1}$ that allowed the EDM of quite complex SiC shapes [11].

During the last years, graphene, in the form of graphene nanoplatelets (GNPs) or graphene oxide (GO) sheets, has become an extraordinary filler to enhance the electrical response of low conductor ceramics such as $\mathrm{Al}_{2} \mathrm{O}_{3}$ [12], $\mathrm{ZrO}_{2}$ [13], $\mathrm{Si}_{3} \mathrm{~N}_{4}$ [14] or $\mathrm{B}_{4} \mathrm{C}$ [15]. Some of the present authors were also able to increase the electrical conductivity 


\section{Experimental procedure}

2.1. Materials fabrication. Five different SiC-based materials were chosen to explore their EDM performances (Table 1), in particular, three monolithic SiC ceramics showing distinct properties and two SiC/GNPs nanocomposites containing 10 and 20 vol.\% of GNPs. Specimens of one of the monolithic SiC ceramics were commercially manufactured (CD110 grade, CeramTec, Germany); whereas for the rest of compositions fully dense specimens were produced in-house according to the 
experimental procedure described elsewhere [16,21]. In brief, SiC/GNPs powders were processed by mixing and sonicating two isopropyl alcohol suspensions independently prepared: one containing commercial GNPs (type N006, Angstron Materials Inc., USA) that were dispersed through a sonication process; and another SiC-based suspension consisting on the attrition milled ceramic powder composition - $93 \mathrm{wt} \% \%$ of micro-sized $\beta$-SiC (BF-17A, H.C. Starck, Germany), 5 wt.\% of $\mathrm{Y}_{2} \mathrm{O}_{3}$ (Grade C,H.C. Starck, Germany), and 2 wt.\% of $\mathrm{Al}_{2} \mathrm{O}_{3}$ (SM8, Baikowski Chimie, France). The dried and sieved SiC/GNPs powder mixtures (labelled as 10GNPs and 20GNPs for 10 and 20 vol.\% GNPs contents, respectively) were then spark plasma sintered (SPS, Dr. Sinter, SPS-510CE, Japan) into disc specimens of $20 \mathrm{~mm} \times 3 \mathrm{~mm}$ at $180{ }^{\circ} \mathrm{C}$ for $5 \mathrm{~min}$, applying a uniaxial pressure of $50 \mathrm{MPa}$ during the heating cycle, and using a vacuum atmosphere of $\sim 6 \mathrm{~Pa}$. Monolithic SiC specimens ( 0 vol.\% GNPs) were equally processed from the ceramic powders. Micro-sized and nano-sized $\beta$-SiC (NanoAmor, USA) were employed as $\mathrm{SiC}$ raw powder into the monolithic ceramic composition. Accordingly, the manufactured monolithic $\mathrm{SiC}$ specimens were labelled as $\mu-\mathrm{SiC}$ and $\mathrm{n}-$ $\mathrm{SiC}$, respectively; meanwhile the commercial one was identified as C-SiC. Table 1 collects the different materials and their main properties.

Table 1. Materials selected for EDM tests and their main morphological characteristics and properties $[16,18,21,22]$ : mean particle size $\left(\mathrm{d}_{50}\right)$, flexural strength $\left(\sigma_{\mathrm{f}}\right)$, fracture toughness $\left(\mathrm{K}_{\mathrm{IC}}\right)$, electrical conductivity $\left(\sigma_{\mathrm{e}}\right)$, and thermal conductivity $\left(\mathrm{k}_{\mathrm{T}}\right)$. Transport data $\left(\sigma_{\mathrm{e}}\right.$ and $\left.\mathrm{k}_{\mathrm{T}}\right)$ in the parallel $(\|)$ and perpendicular $\left({ }^{\perp}\right)$ directions to the SPS pressing axis are also included for some materials. ${ }^{\dagger}$ Data reported by the supplier. ${ }^{*} \mathrm{~K}_{\mathrm{IC}}$ value 
estimated by Vickers indentations at $49 \mathrm{~N}$. For the rest of materials $\mathrm{K}_{\mathrm{IC}}$ was assessed by the surface crack in flexure method.

\begin{tabular}{|c|c|c|c|c|c|c|}
\hline Material & Label & $\begin{array}{c}\mathbf{d}_{\mathbf{5 0}} \\
(\mu \mathrm{m})\end{array}$ & $\begin{array}{c}\sigma_{\mathbf{f}} \\
(\mathbf{M P a})\end{array}$ & $\begin{array}{c}\mathrm{K}_{\mathrm{IC}} \\
\left(\mathrm{MPa} \mathrm{m}^{1 / 2}\right)\end{array}$ & $\begin{array}{c}\sigma_{\mathrm{e}} \\
\left(\mathrm{S} \cdot \mathbf{m}^{-1}\right)\end{array}$ & $\begin{array}{c}\mathbf{k}_{\mathrm{T}} \\
\left(\mathbf{W} \cdot \mathbf{m}^{-1} \cdot \mathbf{K}^{-1}\right)\end{array}$ \\
\hline $\begin{array}{l}\text { Commercial } \\
\text { monolithic } \\
\text { SiC }\end{array}$ & $\mathrm{C}-\mathrm{SiC}$ & $3-5^{\dagger}$ & $440^{\dagger}$ & $3.8^{\dagger}$ & $2 \times 10^{-6 \dagger}$ & $100^{\dagger}$ \\
\hline $\begin{array}{l}\text { Monolithic } \\
\text { Nano SiC }\end{array}$ & $\mathrm{n}-\mathrm{SiC}$ & 0.4 & --- & $3.5^{*}$ & $\sim 33$ & $\begin{array}{l}29(\|) \\
67(\perp)\end{array}$ \\
\hline $\begin{array}{l}\text { Monolithic } \\
\text { Micro SiC }\end{array}$ & $\mu-\mathrm{SiC}$ & 0.6 & 373 & 3.2 & $\begin{array}{l}1(\|) \\
5(\perp)\end{array}$ & $\begin{array}{l}43(\|) \\
65(\stackrel{\perp}{ })\end{array}$ \\
\hline $\begin{array}{l}\text { Micro SiC/10 } \\
\text { vol.\%GNPs }\end{array}$ & 10GNPs & 0.6 & 602 & 5.9 & $\begin{array}{l}158(\|) \\
922(\perp)\end{array}$ & $\begin{array}{l}33(\|) \\
73(\perp)\end{array}$ \\
\hline $\begin{array}{l}\text { Micro SiC/20 } \\
\text { vol.\%GNPs }\end{array}$ & 20GNPs & 0.7 & 401 & 4.1 & $\begin{array}{c}919(\|) \\
4380(\perp)\end{array}$ & $\begin{array}{l}25(\|) \\
84(\stackrel{\perp}{ })\end{array}$ \\
\hline
\end{tabular}

It is important to remark that $\mu-\mathrm{SiC}$ and $\mathrm{n}-\mathrm{SiC}$ ceramics contained $\sim 3-4 \mathrm{vol} . \%$ of graphene multilayers, which were in-situ grown at the $\mathrm{SiC}$ grain boundaries during the SPS process [21]. Besides, both types of graphene fillers, the in-situ grown and the added GNPs, appeared into the material preferentially oriented with their basal (ab) 

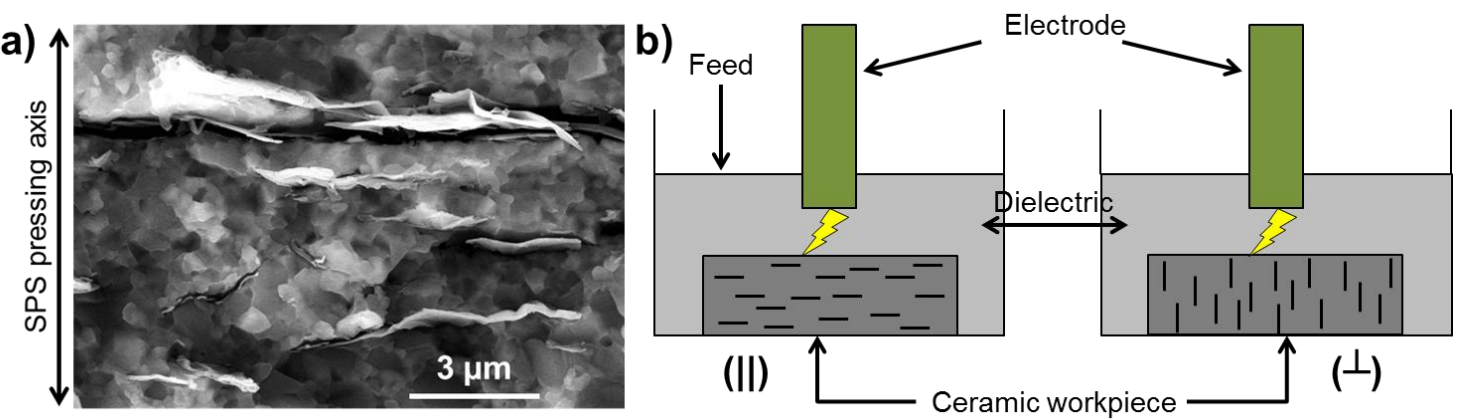

Figure 1. a) SEM micrograph of the fracture surface of 10GNPs composite showing the preferential orientation of the GNPs with their basal plane perpendicular to the SPS pressing axis. b) Scheme of the EDM tests performed on the parallel $(\|)$ and perpendicular $(\stackrel{\perp}{\perp}$ directions of the materials with respect to the SPS pressing axis.

To explore the EDM performance of the ceramics and nanocomposites, three different EDM energy conditions were selected (Table 2) from preliminary trials that enabled a stable EDM process in all materials. In particular, the selected energy settings 
corresponded to conventional fine machining (EDM-F) and rough and fast machining (EDM-R1 and EDM-R2) processes. In the case of EDM-R1 and EDM-R2, the generator only allows one discharge per pulse width, while for EDM-F a larger number of discharges having shorter on times takes place. The main difference between rough conditions is that the applied voltage is higher for EDM-R2 (Table 2). A tungsten carbide rod with a diameter of $300 \mu \mathrm{m}$ was used as tool electrode and microgrooves were machined into the materials with the rotating microrods. The tests were carried out using a machining depth and length of $50 \mu \mathrm{m}$ and $200 \mu \mathrm{m}$, respectively, and an infeed of $10 \mu \mathrm{m}$. IME 110 (Oelheld GmbH, Germany) was used as dielectric fluid. All the materials were EDMed in the $(\|)$ direction (Fig. 1b). In addition, EDM tests were also carried out in the $(\perp)$ direction (Fig. 1b) for the materials presenting a clear anisotropy on their electrical and thermal conductivities (Table 2).

The material removal rate (MRR) was calculated using the process time and the removed volume optically measured with a coordinate measuring machine (Werth Videocheck HA400, Germany). The surface roughness $\left(S_{\mathrm{q}}\right)$ of the machined surface was optically measured with a white light interferometer (Zygo, USA). The electrode tool wear ratio (EWR) was assessed from the ratio between the electrode wear volume and the removed workpiece volume. The analysis of the machined surfaces was done by scanning electron microscopy (SEM, DSM 962, Zeiss, Germany) and micro-Raman spectroscopy (Alpha300 WITec GmbH, Germany) using the $532 \mathrm{~nm}$ laser wave-length excitation. Raman maps of $25 \times 25$ pixels, recording one spectrum per pixel and using 1 $\mathrm{s}$ of acquisition time, were acquired on $50 \times 50 \mu \mathrm{m}^{2}$ scanned areas. The micro hardness (H) of some of the materials was determined on the unmachined and EDMed surfaces at room-temperature (MHT-10, Anton Paar-Paar Physica, USA) using a diamond indenter 
Table 2. Parameters of the different fine (EDM-F) and rough (EDM-R) machining conditions.

\begin{tabular}{|c|c|c|c|c|}
\hline Energy & Voltage & Current & Frequency & Pulse width \\
conditions & $(\mathbf{V})$ & (index) & $(\mathbf{k H z})$ & $(\boldsymbol{\mu s})$ \\
\hline EDM-F & 200 & 1 & 100 & 1 \\
\hline EDM-R1 & 140 & 25 & 100 & 1 \\
\hline EDM-R2 & 200 & 25 & 100 & 1 \\
& & & & \\
\hline
\end{tabular}

\section{Results and discussion}

The EDM performance of the different tested materials, machined in the $(\|)$ direction, versus the energy conditions is collected in Figure 2. At first glance, the addition of GNPs to SiC ceramics dramatically increased the MRR (Fig. 2a), ranging, for EDM-F testing condition, from $0.37 \times 10^{-2} \mathrm{~mm}^{3} \cdot \mathrm{min}^{-1}(\mathrm{C}-\mathrm{SiC})$ to $1.05 \times 10^{-2}$ $\mathrm{mm}^{3} \cdot \mathrm{min}^{-1}(20 \mathrm{GNPs})$, which represents an augment in MRR of $\sim 186 \%$. This outstanding increment could be explained by the electrical and thermal properties of the EDMed materials. As it is shown in Table $1, \sigma_{\mathrm{e}}$ considerably augments in the $(\|)$ direction while $\mathrm{k}_{\mathrm{T}}$ moderately decreases, both when compared with monolithics having similar matrices characteristics. In general, a high electrical conducting workpiece would enlarge the probability for producing successful discharges during the EDM 
process, increasing the material removal. Actually, Figure 3 a shows a strong and direct increasing dependence of MRR with $\sigma_{\mathrm{e}}$ (for values above $1 \mathrm{~S} \cdot \mathrm{m}^{-1}$ ), i.e., with the GNPs content in the case of the nanocomposites. In addition, comparing the MRR response of the different monolithic $\mathrm{SiC}$, the best performance was attained for $\mathrm{n}-\mathrm{SiC}$ ceramics, which exhibits the highest electrical conductivity (Table 1) due to both the graphenelike network formed in-situ and the strong doping during its sintering [21,23].

a)

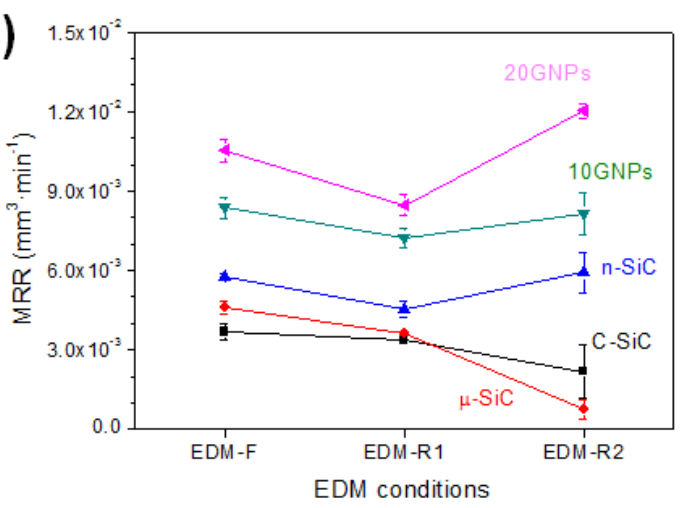

b)

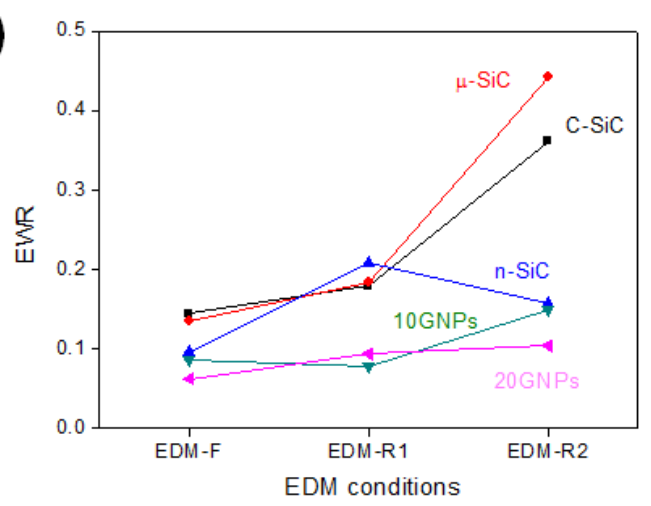

c)

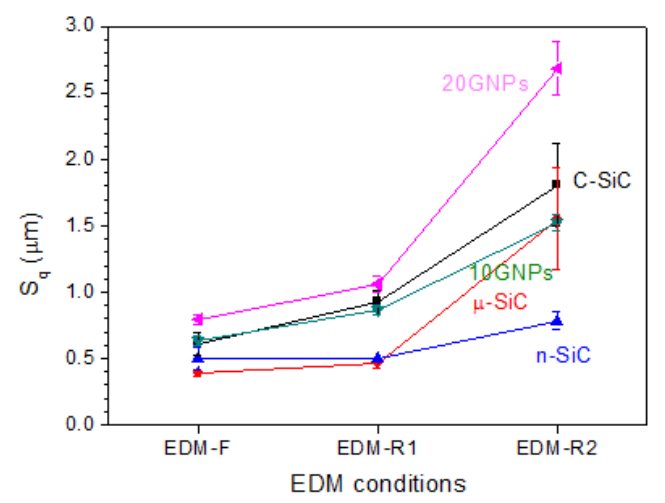

Figure 2. a) Material removal rate (MRR), b) electrode wear rate (EWR), and c) surface roughness $\left(\mathrm{S}_{\mathrm{q}}\right)$ as a function of the EDM conditions for the different ceramic materials machined in the $(\|)$ configuration. 
The thermal conductivity of the workpiece also influences the EDM process by affecting the dissipation of the generated heat and the material removal by thermal spalling. In this way, MRR data exhibited an inverse dependence with $\mathrm{k}_{\mathrm{T}}$ (Fig. 3b). Besides, as $\mathrm{k}_{\mathrm{T}}$ decreases (GNPs nanocomposites), heat losses diminish and the energy process is much focused to melt the workpiece, improving the EDM performance. Therefore, the better machining response of GNPs nanocomposites is explained by the combined effect of an increasing electrical conductivity and decreasing thermal conductivity.

a)

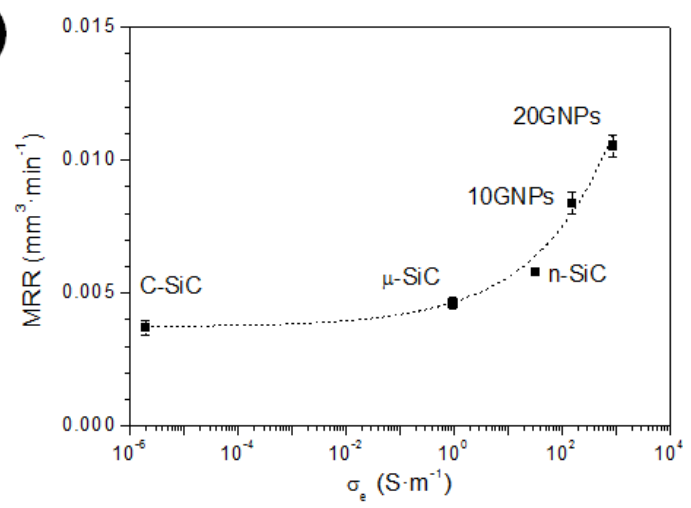

b)

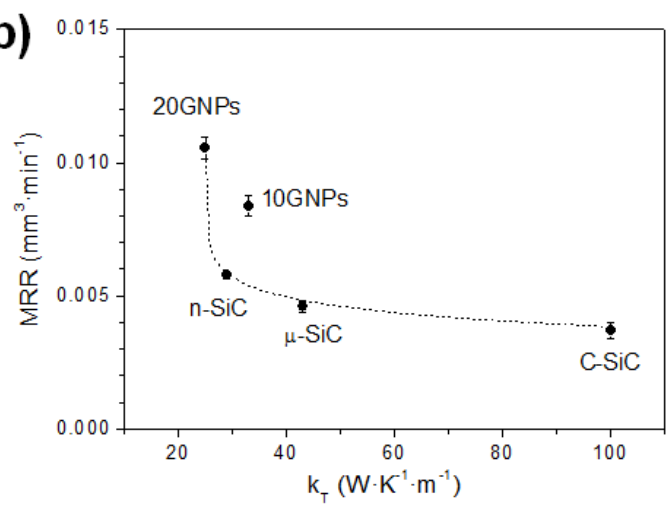

C)

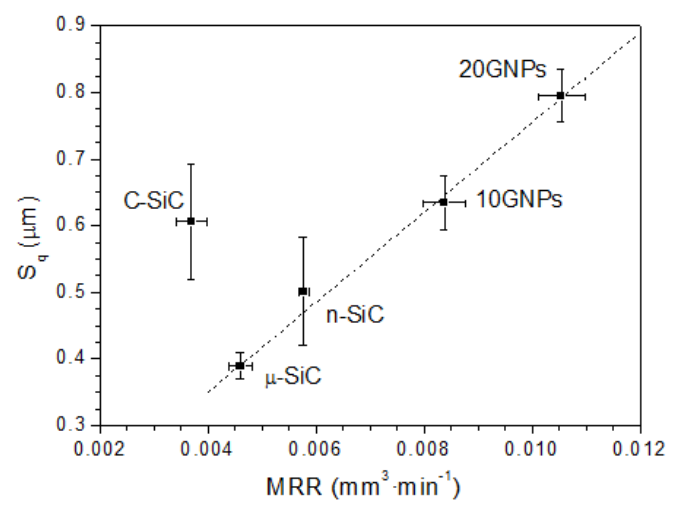

Figure 3. a) Material removal rate (MRR) at EDM-F as a function of the electrical and b) thermal conductivities of the EDMed materials in the $(\|)$ configuration. (c) Surface roughness $\left(\mathrm{S}_{\mathrm{q}}\right)$ evolution versus material removal rate (MRR) using EDM-F settings and (\|) configuration. 
At a first glance, the effect of the machining energy parameters on MRR does not follow a clear trend (Fig. 2a). Initially, larger MRR values should be expected for rough machining EDM-R1 and EDM-R2 settings. This is not the case for EDM-R1, where MRR decreased for all the materials probably due to both the lower spark voltage and the limitation of one discharge per pulse width, in comparison with higher voltage and the larger number of discharges for EDM-F. Despite the discharges limitation of EDM-R2, its higher voltage augmented MRR for the materials machined using EDM (n-SiC, 10GNPs, 20GNPs) up to similar or even higher values than those attained for EDM-F. However, when AEM testing C-SiC and $\mu$-SiC materials, MRR further decreased due to the excessive generation of pyrolytic carbon which was not sufficiently flushed away, causing instabilities in the machining process.

EWR for all the materials is plotted as a function of the machining conditions in Fig. 2b. The results evidence that, independently of the EDM conditions, GNPs nanocomposites led to lower EWR values $(<0.15)$, which is a clear indicator of their finer dimensional precision and better EDM performance. In particular, 20GNPs nanocomposite reached at EDM-F an EWR value of up to $132 \%$ and $55 \%$ lower than monolithic SiC ceramics machined with and without AEM, respectively. Besides, a larger GNPs content provided a better EWR response (37\% at EDM-F for 20 vol. $\%$ of GNPs). In general, EWR significantly augmented for non-conducting materials as the energy parameters increased, reaching values above 0.4 .

The surface analysis by SEM of the machined workpieces (Figure 4) evidenced the formation of either discharge craters in the case of AEMed materials (C-SiC and $\mu$ - 
SiC, Figs. 4a,c) or a recast layer over the machined surface for the rest of conducting materials (n-SiC and GNPs nanocomposites, Figs. 4b,d,e), the latter confirming a removal mechanism by melting process of the liquid-phase sintered materials.

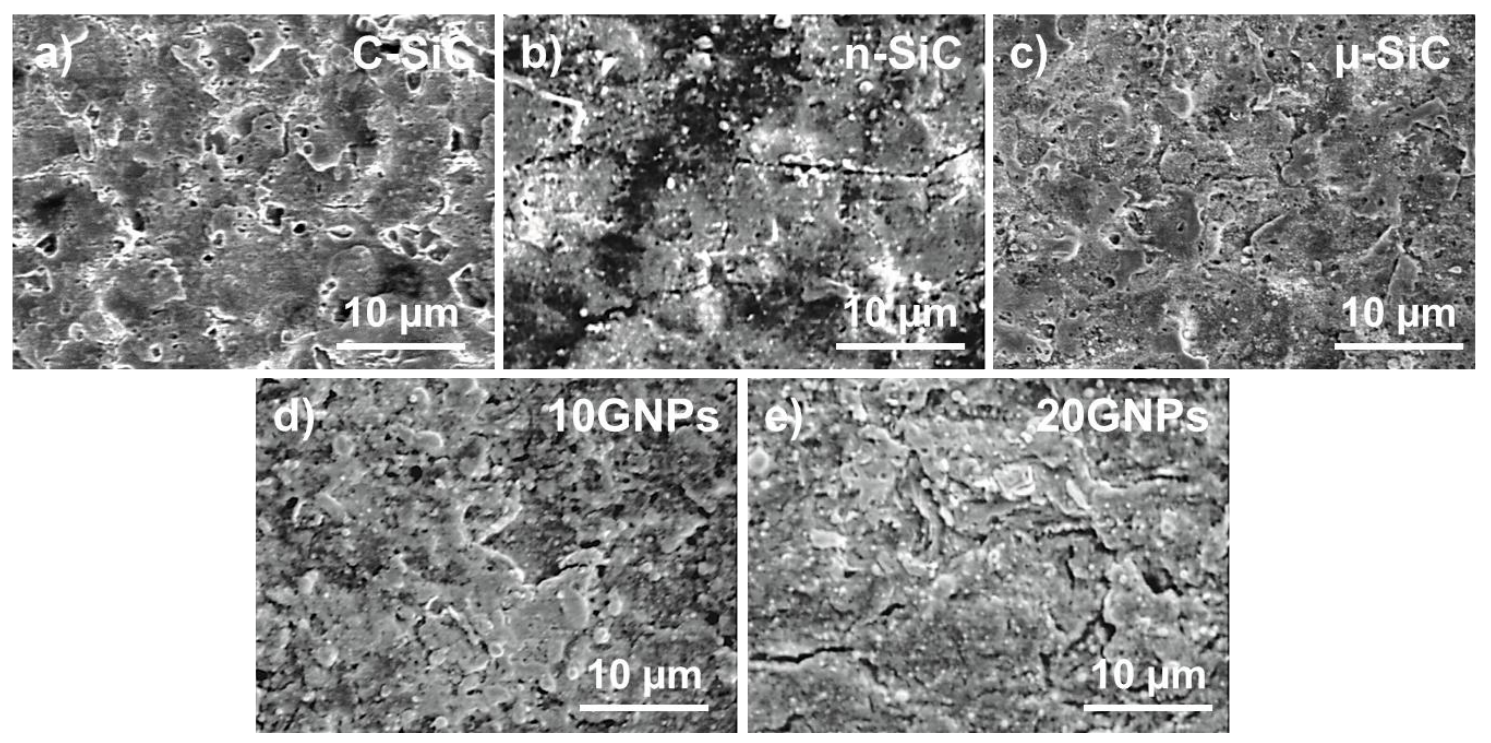

Figure 4. SEM micrographs of the EDMed surfaces at EDM-F in the $(\|)$ configuration for: a) C-SiC, b) n-SiC, c) $\mu$-SiC, d) 10GNPs, and e) 20GNPs materials.

An important issue in the EDM process is the surface roughness of the machined workpieces, which must be low enough to avoid further polishing treatments that would raise the final production costs. As expected, the fine machining setting conditions (EDM-F) produced $S_{\mathrm{q}}$ values below $1 \mu \mathrm{m}$ for all materials (Fig. 2c); whereas $S_{\mathrm{q}}$ increased for rough machining conditions, especially for EDM-R2 (up to $2.7 \mu \mathrm{m}$ for 20GNPs nanocomposite), where an increase of the energy input into the surface occurred. In addition, when plotting $\mathrm{S}_{\mathrm{q}}$ versus MRR at EDM-F, a clear relationship was observed (Fig. 3c). In this way, the roughness of the machined workpieces linearly augmented with the MRR except for C-SiC. The unexpected high $\mathrm{S}_{\mathrm{q}}$ attained for this 
ceramic material considering its relatively low MRR could be explained by its large grain size $(3-5 \mu \mathrm{m})$, almost one order of magnitude bigger than for the rest of materials (Table 1), that would produce deeper craters and, hence, higher $S_{\mathrm{q}}$. In view of EDM-F led to the best EDM performance of the tested materials in terms of high MMR, and low EWR and $S_{\mathrm{q}}$, this energy parameter was selected for the following studies.

Micro-Raman spectroscopy can also be used as tool to analyse the surface damage of the EDMed surfaces. In this way, n-SiC ceramics and 10GNPs and 20GNPs nanocomposites, chosen by their better EDM performance, were characterized by Raman spectroscopy (Figure 5). The unmachined surfaces (Fig. 5a) of the GNPs nanocomposites exhibited Raman peaks centred at $\sim 805 \mathrm{~cm}^{-1}$ and $\sim 975 \mathrm{~cm}^{-1}$, corresponding to the transverse-optical (TO) and longitudinal optical (LO) modes of $\beta$ SiC [24], respectively, and the three characteristic bands of graphitic species associated to GNPs [25], i.e., D- $\left(\sim 1360 \mathrm{~cm}^{-1}\right)$, G- $\left(\sim 1595 \mathrm{~cm}^{-1}\right)$, and 2D-bands $\left(\sim 2717 \mathrm{~cm}^{-1}\right)$. The $\mathrm{n}$-SiC ceramics also present these bands, although less intense, due to the in-situ growth of a graphene network during the ceramic densification by SPS [21], and only the SiCTO band at $\sim 805 \mathrm{~cm}^{-1}$ is observed for this material reflecting its high doping level [23]. After the EDM tests (Fig. 5b), the SiC signal in all materials almost disappeared, whereas a new peak at $\sim 520 \mathrm{~cm}^{-1}$ associated to silicon (Si) was detected which infers the decomposition of $\mathrm{SiC}$ due to the high local temperatures reached during the machining processes. Regarding the GNPs, the EDMed surfaces showed the same characteristic bands than the untested ones, although their intensity ratios substantially varied. As it can be seen in Fig. 5c, the intensity ratio between D and G-bands $\left(\mathrm{I}_{\mathrm{D}} / \mathrm{I}_{\mathrm{G}}\right)$, commonly employed as tool to estimate the crystallinity (or defective) degree of the graphene species, dramatically increased after the EDM process in all materials, from 
0.95 to 1.37 for $\mathrm{n}-\mathrm{SiC}, 0.26$ to 1.22 for $10 \mathrm{GNPs}$, and 0.36 to 0.92 for $20 \mathrm{GNPs}$. These results mean that graphene flakes on the machined surface became highly damaged after the severe testing conditions used for EDM.
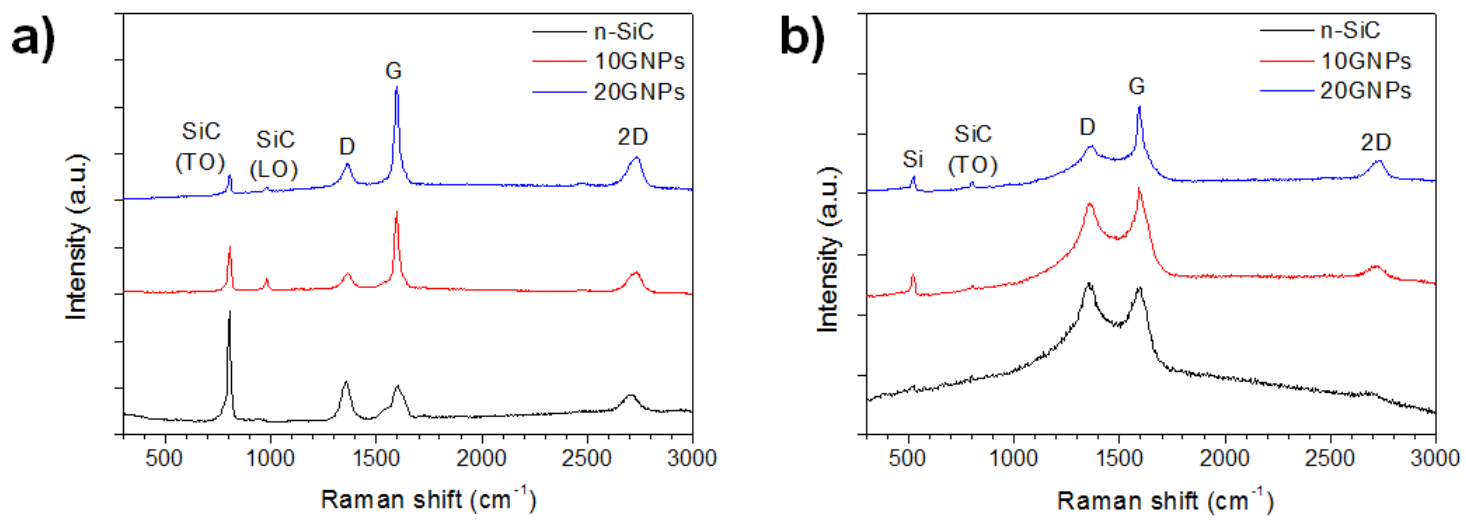

\begin{tabular}{|l|c|c|}
\hline \multicolumn{1}{|c|}{$\mathrm{I}_{\mathrm{D}} / \mathrm{I}_{\mathrm{G}}$} & Unmachined & EDMed \\
\hline $\mathrm{n}-\mathrm{SiC}$ & 0.95 & 1.37 \\
\hline $10 \mathrm{GNPs}$ & 0.26 & 1.22 \\
\hline $20 \mathrm{GNPs}$ & 0.36 & 0.92 \\
\hline
\end{tabular}

Figure 5. Average Raman spectra of the n-SiC ceramics and 10GNPs and 20GNPs nanocomposites before (a) and after (b) EDM tests performed at EDM-F in the (\|) configuration. c) Table summarizing the Raman $I_{D} / I_{G}$ values for the unmachined and EDMed surfaces.

As it was previously reported by some of the authors [17], the addition of GNPs to $\mathrm{SiC}$ decreased the hardness due to the sliding phenomenon of the graphene layers within the nanoplatelets. After EDM, the surface damage of the machined workpiece, evidenced by the decomposition of $\mathrm{SiC}$, and in the case of nanocomposites by the GNPs degradation as well, led to the reduction of the hardness. After EDM process, $\mathrm{H}$ values 
for both nanocomposites were very similar, which means that hardness is controlled by the recast layer.

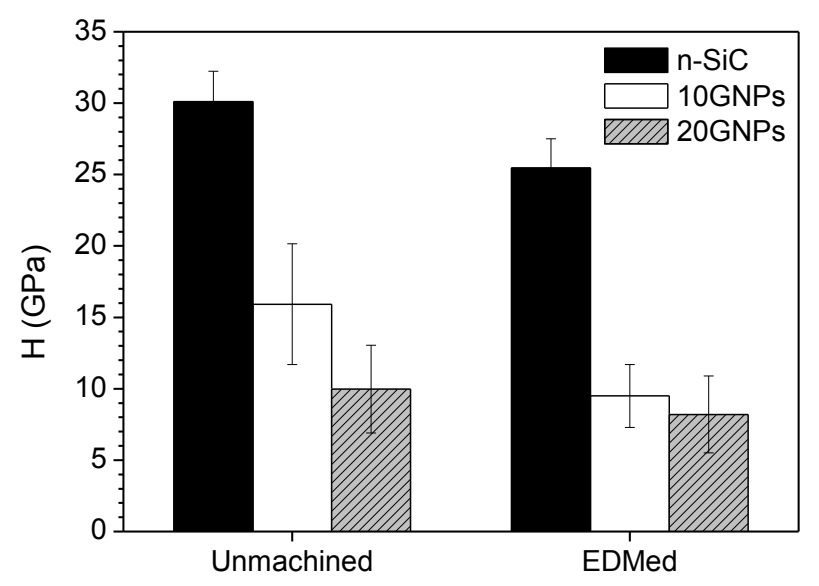

Figure 6. Hardness $(\mathrm{H})$ tested in the $(\|)$ direction for the unmachined and EDMed (EDM-F) surfaces for n-SiC, 10GNPs, and 20GNPs materials.

As a proof of concept of the excellent EDM performance attained for GNPs nanocomposites in absence of the AEM, different high quality micropillars and microholes were machined (Figure 7). The EDMed structures showed in all cases very sharp and defined edges with no sign of damage, proving the benefits of adding graphene fillers to low electrically conducting ceramics for EDM microfeatures with high structural stability. 

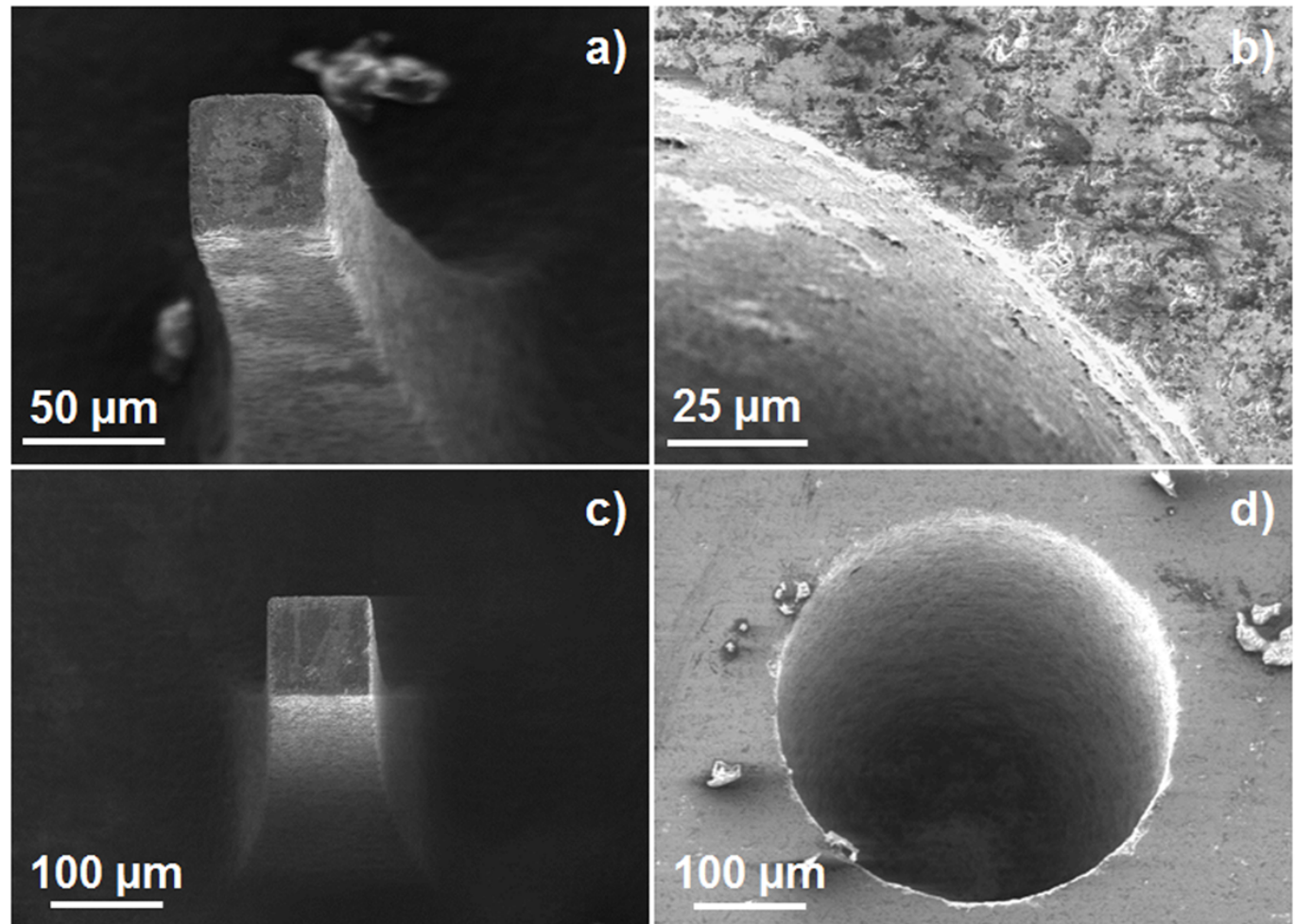

c)

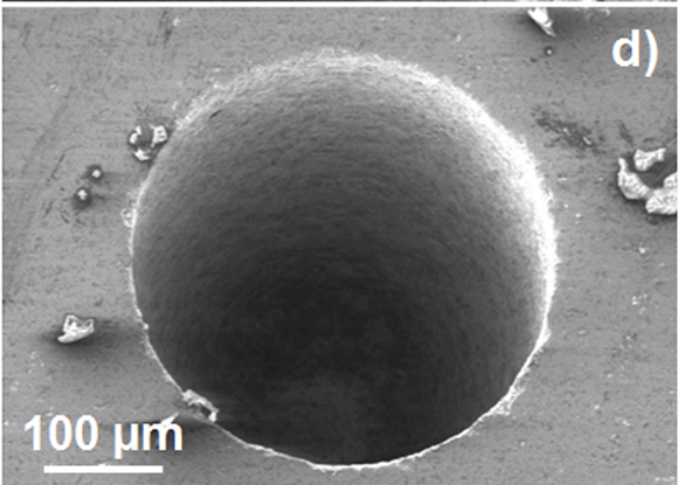

Figure 7. SEM micrographs showing some examples of EDMed features (micropillar and microhole) in the 10GNPs (a,b) and 20GNPs nanocomposites (c,d). High magnification SEM image in b) shows the edge of a microhole.

The EDM performance in the $\left(\perp^{\perp}\right)$ configuration for $\mathrm{n}$-SiC ceramics and GNPs nanocomposites is depicted in Figure 8, where the fine machining conditions (EDM-F) seem to get the best MRR response (Fig. 8a). Interestingly, when comparing MRR for both testing directions at EDM-F (Fig. 8b), similar results were attained except for the 10GNPs nanocomposite, where a 35\% increase was achieved in the $\left({ }^{\perp}\right)$ direction (MRR $\left.\sim 1.1 \times 10^{-2} \mathrm{~mm}^{3} \cdot \mathrm{min}^{-1}\right)$ as compared to data assessed in the $(\|)$ one. This behaviour is explained considering the relationship between the electrical properties and the MRR (Fig. 8c). Actually, 10GNPs shows complete connectivity between the nanoplatelets in 
the $(\stackrel{\perp}{\perp})$ orientation $\left(\sigma_{\mathrm{e}}=922 \mathrm{~S} \cdot \mathrm{m}^{-1}\right)$ but not in the $(\|)$ one $\left(\sigma_{\mathrm{e}}=158 \mathrm{~S} \cdot \mathrm{m}^{-1}\right)$. Therefore, an increase in $\sigma_{\mathrm{e}}$ promoted more efficient electrical discharge and removal mechanisms until the electrical percolation threshold was reached, where the maximum efficiency of the EDM occurred (Fig. 8c). A further increment in $\sigma_{\mathrm{e}}$ above $\sim 900 \mathrm{~S} \cdot \mathrm{m}^{-1}$ had a negligible effect in MRR.
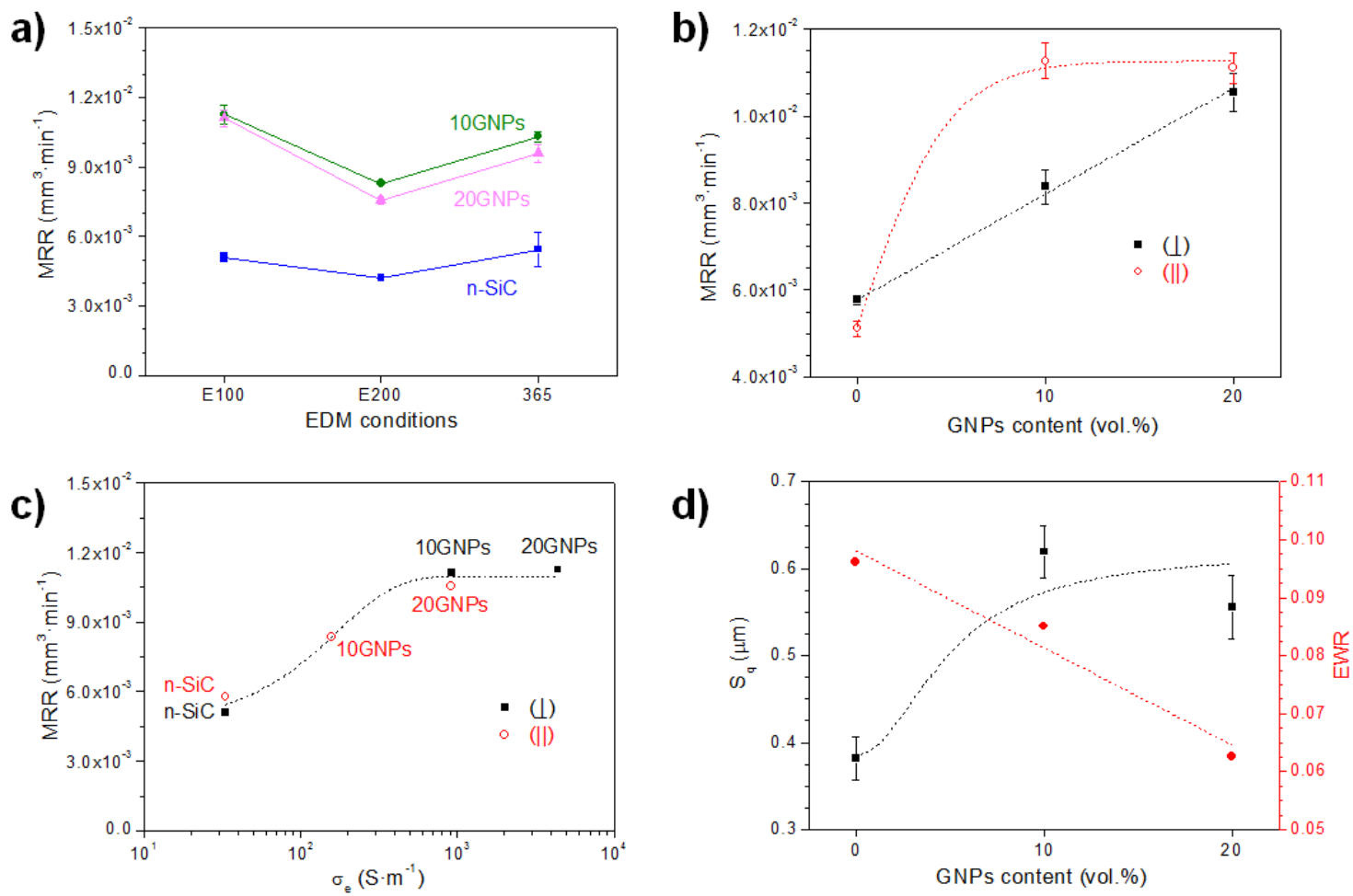

Figure 8. EDM performance of $\mathrm{n}-\mathrm{SiC}$ ceramics and 10GNPs and 20GNPs nanocomposites tested in the $(\stackrel{\perp}{)}$ configuration. a) Material removal rate $(\mathrm{MRR})$ versus EDM conditions, b) MRR as a function of the GNPs content for the $(\perp)$ and $(\|)$ directions at EDM-F, c) relationship between the electrical $\left(\sigma_{\mathrm{e}}\right)$ conductivity and the MRR response using EDM-F settings for both testing directions, and d) surface roughness $\left(S_{\mathrm{q}}\right)$ and electrode wear rate (EWR) versus GNPs content at EDM-F in the $(\stackrel{\perp}{)}$ configuration. 
As it was also observed for the $(\|)$ orientation, $S_{\mathrm{q}}$ scaled with MRR showing a similar trend (Fig. 8d), although the surface finishing kept quite smooth $(<0.7 \mu \mathrm{m})$ for all materials. Finally, the clear benefits of adding GNPs into EWR are shown in Fig. 8d, where an almost linear improvement of the dimensional precision (lower EWR) with the GNPs content was evidenced.

The SEM observations of the surfaces EDMed in the $(\perp)$ direction showed the formation of a recast layer (Figure 9), as occurred for the $(\|)$ surfaces. GNPs perpendicularly oriented to the SPS pressing axis were perceived for this orientation (pointed by arrows in Figs. 9b,c).
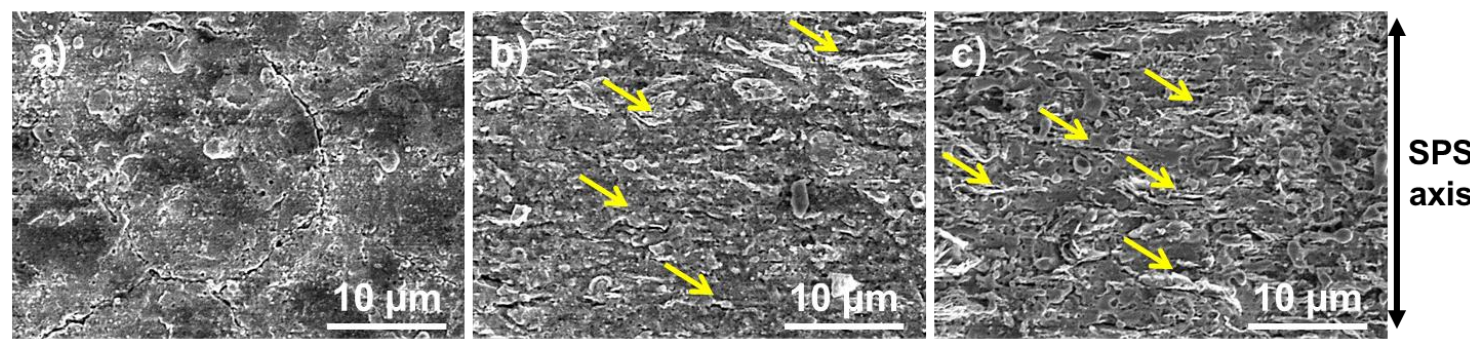

Figure 9. SEM micrographs of the EDMed surfaces at EDM-F in the $(\perp)$ configuration for: a) n-SiC, b) 10GNPs, and c) 20GNPs materials. The arrows in (b) and (c) point the GNPs.

It can be concluded that the testing orientation has a limited influence in the EDM performance of materials with low (n-SiC) and high (20GNPs) amounts of GNPs, but it is extremely important for intermediate contents (10GNPs), the EDM response being much better for the $(\stackrel{\perp}{\perp}$ direction and closer to that of 20GNPs. 


\section{Conclusions}

The EDM performance of SiC ceramics is clearly enhanced by adding graphene fillers to the ceramic matrix, allowing to machine microfeatures with high level of accuracy and surface roughness below $1 \mu \mathrm{m}$. A relationship between this outstanding EDM response of SiC/GNPs nanocomposites and the transport properties is established, showing a strong and direct dependence of MRR with the electrical conductivity of all materials. The nanocomposite with the highest GNPs content (20 vol.\%) exhibits, as compared to monolithic SiC ceramics, an increment on MRR of up to $186 \%$ jointly with a reduction on EWR of up to $132 \%$. The machining orientation affects the EDM performance of GNPs nanocomposites for intermediate contents where the electrical percolation is attained only in the direction perpendicular to the SPS pressing axis. The employ of EDM on SiC/graphene materials opens new opportunities for manufacturing complex SiC-based microcomponents to be used, among others, in the electronic and energy fields.

\section{Acknowledgements}

This work was supported by the Spanish Government (MAT2012-32944 and MAT2015-67437-R projects). 


\section{References}

[1] G. Roewer, U. Herzog, K. Trommer, E. Müller, S. Frühauf, Silicon carbide-a survey of synthetic approaches, properties and applications, High Perform. non-oxide ceram.: I Struct. Bond. 101 (2002) 59-135.

[2] K. A. Schwetz, Silicon carbide based hard materials, Handbook of Ceramic Hard Materials. Wiley Online Library, Weinhein, 2008.

[3] K. H Ho, S. T Newman, State of the art electrical discharge machining (EDM), Int. J. Mach. Tool. Manu. 43 (13) (2003) 1287-1300.

[4] W. König, D. F. Dauw, G. Levy, U. Panten, EDM-Future Steps towards the Machining of Ceramics, CIRP Ann.-Manuf. Techn. 37 (2) (1998) 623-631.

[5] Y. Fukuzawa, T. Tani, E. Iwane, N. Mohri, A new machining method for insulating ceramics with an electrical discharge phenomenon, J. Ceram. Soc. Japan 103 (1995) 987-992.

[6] Y. Fukuzawa, N. Mohri, T. Tani, Electrical discharge machining method of insulating ceramics, J. Japan Soc. Precision Eng. 71 (5) (2005) 541-544.

[7] F. Zeller, T. Hösel, C. Müller, H. Reinecke, Microstructuring of non-conductive silicon carbide by electrical discharge machining, Microsyst. Technol. 20 (10-11) (2014) 1875-1880.

[8] R. Bajaj, A. K. Tiwari, A. R. Dixit, Current trends in electric discharge machining using micro and nano powder materials- A Review, Mater. Today Proc. 2 (4-5) (2015) $3302-3307$. 
[9] P. J. Liew, J. Yan, T. Kuriyagawa, Carbon nanofiber assisted micro electro discharge machining of reaction-bonded silicon carbide, J. Mater. Proc. Technol. 213 (7) (2013) 1076-1087.

[10] S. Clijsters, K. Liu, D. Reynaerts, B. Lauwers, EDM technology and strategy development for the manufacturing of complex parts in SiSiC, J. Mater. Proc. Technol. 210 (4) (2010) 631-641.

[11] Y.-W. Kim, K. J. Kim, H. C. Kim, N.-H. Cho, K.-Y. Lim, Electrodischargemachinable silicon carbide ceramics sintered with yttrium nitrate, J. Am. Ceram. Soc. 94 (4) (2011) 991-993.

[12] Y. Fan, L. Wang, J. Li, J. Li, S. Sun, F. Chen, 1. Chen, W. Jiang, Preparation and electrical properties of graphene nanosheet/ $\mathrm{Al}_{2} \mathrm{O}_{3}$ composites, Carbon 48 (6) (2010) 1743-1749.

[13] J.-H. Shin, S.-H. Hong, Fabrication and properties of reduced graphene oxide reinforced yttria-stabilized zirconia composite ceramics, J. Eur. Ceram. Soc. 34 (5) (2014) 1297-1302.

[14] C. Ramírez, S. M. Vega-Díaz, A. Morelos-Gómez, F. M. Figueiredo, M. Terrones, M. I. Osendi, M. Belmonte, P. Miranzo, Synthesis of conducting graphene $/ \mathrm{Si}_{3} \mathrm{~N}_{4}$ composites by spark plasma sintering, Carbon 57 (2013) 425-432.

[15] Y. Tan, H. Luo, H. Zhang, S. Peng, Graphene nanoplatelet reinforced boron carbide composites with high electrical and thermal conductivity, J. Eur. Ceram. Soc. 36 (11) (2016) 2679-2687. 
[16] B. Román-Manso, E. Domingues, F. M. Figueiredo, M. Belmonte, P. Miranzo, Enhanced electrical conductivity of silicon carbide ceramics by addition of graphene nanoplatelets, J. Eur. Ceram. Soc. 35 (10) (2015) 2723-2731.

[17] J. Llorente, B. Román-Manso, P. Miranzo, M. Belmonte, Tribological performance under dry sliding conditions of graphene/silicon carbide composites, J. Eur. Ceram. Soc. 36 (3) (2016) 429-435.

[18] M. Belmonte, A. Nistal, P. Boutbien, B. Román-Manso, M. I. Osendi, P. Miranzo, Toughened and strengthened silicon carbide ceramics by adding graphene-based fillers, Scripta Mater. 113 (2016) 127-130.

[19] D. Hanaoka, Y. Fukuzawa, C. Ramirez, P. Miranzo, M.I. Osendi, M. Belmonte, Electrical discharge machining of ceramic/carbon nanostructure composites, Procedia CIRP 6 (2013) 95-100.

[20] J.-W. Sung, K.-H. Kim, M.-C. Kang, Effects of graphene nanoplatelet contents on material and machining properties of GNP-dispersed $\mathrm{Al}_{2} \mathrm{O}_{3}$ ceramics for micro-electric discharge machining, Int. J. Precision Eng. Manufact-Green Technol. 3 (3) (2016) 247252.

[21] P. Miranzo, C. Ramirez, B. Román-Manso, L. Garzon, H. R. Gutierrez, M. Terrones, C. Ocal, M.I. Osendi, M. Belmonte, In situ processing of electrically conducting graphene/SiC nanocomposites, J. Eur. Ceram. Soc. 33 (10) (2013) 16651674. 
[22] B. Román-Manso, Y. Chevillotte, M. I. Osendi, M. Belmonte, P. Miranzo, Thermal conductivity of silicon carbide composites with highly oriented graphene nanoplatelets, J. Eur. Ceram. Soc. 36 (16) (2016) 3987-3993.

[23] P. Miranzo, L. López-Mir, B. Román-Manso, M. Belmonte, M.I. Osendi, C. Ocal, Prominent local transport in silicon carbide composites containing in-situ synthesized three-dimensional graphene networks. J. Eur. Ceram. Soc. 36 (13) (2016), 3073-3081.

[24] S. I. Nakashima, H. Harima, Raman investigation of SiC polytypes, Physica Status Solidi (a) 162(1) (1997), 39-64.

[25] A. C. Ferrari, J. C. Meyer, V. Scardaci, C. Casiraghi, M. Lazzeri, F. Mauri, S. Piscanec, D. Jiang, K. S. Novoselov, S. Roth, A. K. Geim, Raman spectrum of graphene and graphene layers. Phys. Rev. Lett. 97 (2006) 187401-187404. 